Note: this is a post-print draft of the journal article:

Ghosh, R, Gupta, S, Dickinson, A., Browne, M. (2012) "Experimental Validation of Finite Element Models of Intact and Implanted Composite Hemi-pelvises using Digital Image Correlation". Journal of Biomechanical Engineering, 134

The final, fully proofed and peer-reviewed journal article is available from the publisher online, via the following link:

http://asmedl.org/getabs/servlet/GetabsServlet?prog=normal\&id=JBENDY000134000008081003000 001\&idtype=cvips\&gifs=Yes

http://dx.doi.org/10.1115/1.4007173 


\title{
Experimental Validation of Finite Element Models of Intact and Implanted Composite Hemi-pelvises using Digital Image Correlation
}

\author{
Rajesh Ghosh $^{1}$, Sanjay Gupta $^{1}$, Alexander Dickinson $^{2}$, Martin Browne $^{2}$ \\ ${ }^{1}$ Department of Mechanical Engineering, Indian Institute of Technology Kharagpur, \\ Kharagpur 721 302, West Bengal, India
}

${ }^{2}$ Bioengineering Science Research Group, School of Engineering Sciences, University of Southampton, Southampton S017 1BJ, United Kingdom

Corresponding author:

Dr. Sanjay Gupta

Department of Mechanical Engineering

Indian Institute of Technology Kharagpur

Kharagpur 721302

West Bengal, India

Tel: $+91-(0) 3222-282958$

Fax: $+91-(0) 3222-282277$

Email: sangupta@mech.iitkgp.ernet.in

Keywords: pelvis biomechanics, in-vitro testing, Digital Image Correlation, strain gauging, finite element analysis.

Word count: Abstract 189; Manuscript 4576 Submitted to ASME Journal of Biomechanical Engineering 


\begin{abstract}
A detailed understanding of the changes in load transfer due to implantation is necessary to identify potential failure mechanisms of orthopaedic implants. Computational finite element (FE) models provide full field data on intact and implanted bone structures, but their validity must be assessed for clinical relevance. The aim of this study was to test the validity of FE predicted strain distributions for the intact and implanted pelvis using the digital image correlation (DIC) strain measurement technique. FE models of an in-vitro hemi-pelvis test setup were produced, both intact and implanted with an acetabular cup. Strain predictions were compared to DIC and strain rosette measurements. Regression analysis indicated a strong linear relationship between the measured and predicted strains, with a high correlation coefficient $(\mathrm{R}=0.956$ intact, 0.938 implanted $)$ and a low standard error of the estimate $(\mathrm{SE}=$

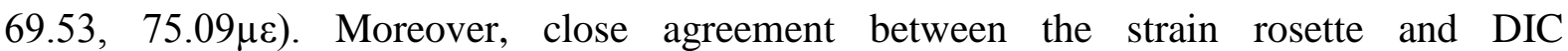
measurements improved confidence in the validity of the DIC technique. The FE model therefore was supported as a valid predictor of the measured strain distribution in the intact and implanted composite pelvis models, confirming its suitability for further computational investigations.
\end{abstract}




\section{Introduction}

Finite element (FE) analysis has been used extensively to test and validate clinical hypotheses and in particular, preclinical evaluations of orthopaedic implant performance. This computational technique provides full field data and allows investigations on the effect of many variables quickly and relatively inexpensively, compared to clinical studies and physical testing. However, the accuracy of the predicted stresses and strains depends on the quality of representation of the FE model compared to the actual conditions. Hence, an assessment of the validity of the FE predictions is required, before the FE model can be further used for clinically relevant investigations.

Experimental measurements using the strain gauge technique have often been employed to validate FE models of intact and implanted bone structures [1 - 4]. Strain gauge measurements yield discrete data, which is an average of the real strains occurring underneath the gauge. Moreover, local surface preparation, instrumentation connected to the gauge and temperature changes can affect strain measurement [5]. Many of these localized measurements are required in biomechanical models, where irregular geometry and material heterogeneity often result in large variation of strain across the structure. Furthermore, if there is a sharp gradient in a strain field, it is unlikely to be captured in discrete experimental measurements. Therefore, continuous field strain data would be of benefit, such as that predicted by FE analysis. Although the photo elastic method has been used in the past to obtain surface strain distributions in a loaded pelvis specimen [6], its applicability is limited by excessive specimen curvature. More recently, digital image correlation (DIC) has evolved as an effective technique for measurement of full field strain on the surface of a loaded specimen [7 - 20]. Other versions of image correlation, such as texture correlation [21 - 23] and $3 \mathrm{D}$ volume correlation $[24,25]$ technique were also used to understand bone mechanical behaviour. 
Full field strain analysis using the DIC technique has been used to understand load transfer across biomechanical specimens at the macro- and micro-scale [7 - 12]. An advantage of the DIC technique is that it is applicable to structures with irregular geometry and heterogeneous material distribution, such as bone. In the study by Sztefek et al. [8], surface strains were measured on mouse tibia specimens using DIC to investigate the change in strain after load-induced bone adaptation. The technique was used to find the differences in two-dimensional strain patterns of the medial cortex of the composite femur, implanted with titanium and carbon-fibre-reinforced plastic femoral prostheses [9]. Everitt et al. [7] investigated acetabular cup deformation for various press-fit designs subjected to rim loading using DIC measurement and FE analysis. However, the acetabular components were loaded at the periphery and, as the authors state, this was not representative of the changes in bone mechanical behavior due to implantation. DIC has also been employed to investigate load transfer in dental implants and to compare splinted and non-splinted implant-supported prostheses with and without proximal contact conditions [12]. More recently, Dickinson et al. [10] validated the full field FE model predicted strain distribution in a composite proximal femur using DIC.

There is a dearth of experimental data on strain measurement in intact and implanted pelvises, which could be used to identify potential links between changes in strain distribution due to implantation and clinical failure mechanisms of the acetabular component. Marked changes in bone strain from the intact bone's equilibrium state have the potential to stimulate an adaptive bone response through remodelling [26], and large increases in strain may indicate a risk of fracture. In earlier experimental validation studies with an intact pelvis, a rigid support structure has been used, which might not be entirely representative of the invivo situation [1 - 3], and to the authors' knowledge there is lack of comparative experimental data on the full field strain distributions across the pelvis before and after 
implantation. In the present study, DIC was employed to assess the validity of FE predicted strain distributions in intact and implanted composite hemi-pelvises. Additionally, discrete principal strain data obtained from DIC were compared with those measured by strain rosettes, fixed at comparable locations on the surfaces of the intact and implanted pelvis. The objective was to conduct a rigorous assessment of the validity of the method of FE model generation and the predicted results, in particular the full field strain distribution in the intact and implanted composite hemi-pelvises. Subsequently, the study is aimed at investigating the effect of deviations in load transfer due to implantation around the acetabulum, which will indicate the stimulus for a bone adaptation response.

\section{Materials and Methods}

The experiments were carried out on a fourth generation composite left hemi-pelvis (3405, Sawbones AG, Sweden) specimen, composed of polyurethane foam with a thin cortical shell layer made of glass-fiber reinforced epoxy. Following the recommended operative technique, one pelvis was implanted with an uncemented acetabular cup of $58 \mathrm{~mm}$ outer diameter and $52 \mathrm{~mm}$ bearing diameter (ADEPT®, MatOrtho, UK), at $45^{\circ}$ inclination and $15^{\circ}$ anteversion $[27,28]$. A diametral interference fit of approximately $1 \mathrm{~mm}$ was used ( $57 \mathrm{~mm}$ ream for $58 \mathrm{~mm}$ external diameter cup), according to typical surgical technique for hip resurfacing $[28,29]$.

\subsection{Experimental set-up and fixation of the pelvises}

The DIC measurements were carried out prior to the strain rosette measurements on the same composite pelvises (intact and implanted), supported and loaded identically in a servo hydraulic Instron testing machine with a $\pm 25 \mathrm{kN}$ load capacity (Instron 8874 , Instron Ltd., UK), for one-to-one comparison of the results. A proprietary fixture, fabricated at the University of Southampton, was used to hold the pelvises at two locations, at the sacroiliac joint and supero-posterior part of the ilium, and the pubis (Figs. 1a and b). In the 
experimental set-up, the pelvis was supported with respect to the modular femoral head in such an orientation that represented the maximum resultant force instant in the gait cycle, shortly after heel strike (Figs. 1a and b) [Bergmann et al., 2001]. Compressive force was applied on the acetabular cavity using a $46 \mathrm{~mm}$ diameter modular femoral head, attached to the test machine actuator. The mechanical test set-ups for the DIC and strain rosette measurements are shown in Figs. 2 and 3, respectively.

The hip joint force is the most dominant force acting on the pelvic bone, which is predominantly transferred through the supero-anterior edge of the acetabulum to the sacroiliac joint $[30,31]$. Due to this edge loading, the lateral cortex of the iliac bone located above the acetabulum is highly stressed [30, 31]. In the experimental set-up, this region of load transfer was chosen as the region of interest for measurement. The effects of load transfer in other regions remote from this area were low in magnitude, resulting in a low signal to noise ratio, thereby inducing more errors in DIC measurements than useful measured data. For the DIC measurements, the region of interest in a specimen was coated with a high contrast, random speckle pattern. White paint was first applied on the surface, followed by black speckling using a compressed air brush. The displacement of the speckle patterns due to load application were recorded using 2 MP digital cameras (Limess GmbH, Germany). Subsequently, VIC 3-D software (Correlated Solutions Inc., SC, USA) was used to record the displacement of the speckle patterns and to calculate the strain in a selected region. According to the manufacturer specification (Limess GmbH, Germany), the precision of DIC measured displacement is 0.01 pixel. Two cameras were used to calculate the surface strains, which were placed at an angle of \pm 10 degrees to the normal direction of the region of interest (Fig. 2). A diffused white light source was used for illumination; this enabled high resolution images while preventing reflections which could have masked the measurements. 
Compressive loads were applied at a rate of $14 \mathrm{~N} \mathrm{sec}^{-1}$ to a maximum of two times body weight, $1400 \mathrm{~N}$.

Additional experiments with the same pelvises were carried out using the more established strain gauging technique, to verify the strain measurements from the DIC. After removal of the white paint and the speckle pattern using acetone and subsequent cleaning by ethyl alcohol, rectangular strain rosettes (SR-4® Strain Gauges, Vishay MicroMeasurements, UK) were attached at pre-determined locations and orientations on the surfaces of the intact and implanted pelvises, in the region of DIC measurement (Fig. 3). The strain rosettes were attached at flat regions of the surface to gain the most accurate results. The location of each rosette was measured with respect to bony landmarks. These data were later used to find comparable point coordinates in the DIC measurement. Similar to the DIC measurement, compressive load was applied at a rate of $14 \mathrm{~N} \mathrm{sec}^{-1}$ to a maximum of $1400 \mathrm{~N}$.

\subsection{Finite Element Modelling and Analysis}

A manufacturer-supplied CAD model of the composite hemi-pelvis was used to generate the 3-D FE model. The precision of the CAD model was $0.38 \mathrm{~mm}$, according to the specification of the NextEngine 3-D Model 2020i Desktop laser scanner (NextEngine Inc., Santa Monica, NC, USA). The femoral head and the acetabular cup were modelled separately using Solid Works software (DS SolidWorks Corp., Concord, MA, USA). Virtual surgical operations, positioning of the cup and the femoral head, and virtual cuts were performed using NURBS modelling software Rhinoceros (Robert McNeel \& Associates, Seattle, WA, USA).

In the experimental set-up, the distances between five predefined bony landmarks on the composite pelvis and a location on the modular femoral head (aligned with the vertical axis of the testing machine) were measured. The solid models of the intact and implanted pelvises were positioned with respect to the femoral head based on these measurements, which 
replicated the orientation of the tested pelvises. In order to generate the volumetric mesh, the solid models were imported into the software ANSYS ICEM CFD (ANSYS Inc. PA, USA), and meshed with four-noded tetrahedral elements with edge lengths varying between $0.5-3$ mm. Finally, this volumetric mesh was imported into Ansys v11 (Ansys Inc. PA, USA) for the FE analysis, in order to convert four-noded tetrahedral to ten-noded tetrahedral elements, thereby increasing the accuracy of the numerical solutions.

The accuracy of the results was checked in a convergence study using three different FE meshes (coarse, medium and fine) and a comparison of the predicted surface strain. In the intact case, the models contained 137432, 269376 and 371958 elements, and the implanted FE models contained 140147, 284993 and 396615 elements. Refinement between coarse and medium meshes changed the peak strain by $6 \%$. However, the maximum peak strain change was reduced to $1 \%$ between the medium and fine meshes, so considering the size of the FE model and the accuracy of the results, the medium sized meshes were judged to be sufficiently accurate. The FE models and selected meshes are shown in Fig. 4.

Linear elastic, isotropic, homogeneous material properties were used for the cancellous foam $(\mathrm{E}=155 \mathrm{MPa})$ and the cortical shell $(\mathrm{E}=16.7 \mathrm{GPa})$ (according to data from the manufacturer). Young's modulus of the cup and the modular femoral head were taken as 197GPa (CoCr alloy). Poisson's ratio for all materials was defined as 0.3. Six node second order asymmetric surface-to-surface contact elements with friction coefficient $\mu=0.1$ were simulated between the acetabular cavity and the modular femoral head for the intact pelvis. In the implanted composite pelvis, a $1 \mathrm{~mm}$ interference fit was assumed between the rim of the implant and the surrounding bone $[28,32]$ and contact elements with $\mu=0.5$ were applied [29, 32]. Frictionless contact was assumed between the modular femoral head and the acetabular cup, representing a well lubricated bearing surface. An augmented Lagrange contact algorithm was used to solve these models [4, 33]. 


\subsection{Experimental error and repeatability}

Five successive experiments were performed for each pelvis specimen to quantify the measurement repeatability. Each specimen was subject to applied loads varying from $600 \mathrm{~N}$ to $1400 \mathrm{~N}$ in steps of $200 \mathrm{~N}$. The strain distribution for the $1400 \mathrm{~N}$ case was considered for comparison of DIC measured and FE predicted strains, the highest load case giving the highest signal: noise ratio.

In order to quantify the DIC measurement sensitivity and identify the region of acceptable accuracy measurements on the surface of the pelvis, five successive unloaded datasets (theoretically with zero strain) were analysed. The sensitivity was calculated to be $< \pm 165 \mu \varepsilon$ (mean \pm three standard deviations) for the intact pelvis and $< \pm 145 \mu \varepsilon$ for the implanted pelvis, which was less than the typical limit of $200 \mu \varepsilon$ reported by the manufacturer for a low curvature region [34]. Subsequently, the region of acceptable accuracy was determined based on these data and indicated by the area enclosed by the white polyline, as shown in Fig. 5. Five repeated loaded datasets corresponding to successive experiments resulted in six sigma experimental error ( \pm three standard deviations) of $< \pm 60 \mu \varepsilon$ for the intact and $< \pm 50 \mu \varepsilon$ for the implanted pelvis. Within this area, the error was found to be minimum, and therefore, the results within the enclosed area were suitable for analysis.

\subsection{Data interpretation and statistical analysis}

The DIC measured full field von Mises strains were compared with the FE strain patterns to validate the predictions of the FE models, and discrete principal strain values obtained from the DIC were compared with the strain rosette measurements. A DIC strain value corresponding to each rosette was calculated as the average value of all point coordinates located underneath the rosette location. The correlation coefficient $(\mathrm{R})$, standard error of the estimate (SE), percentage error (PE) and test statistics value (P-value) of the regression slope (b) were used to evaluate whether a significant relationship existed between the DIC 
measured and FE predicted strain. The percentage error was calculated as the ratio of SE of $b$ to $b$.

\section{Results}

The von Mises strain distributions for both the pelvises are shown in Fig. 5. In the intact pelvis, the distribution of DIC measured and FE predicted strains varied from 0 to $1200 \mu \varepsilon$ within the ROI (Figs. 5a and b). High strains of $600-1200 \mu \varepsilon$ were observed at the superior part of the acetabulum and adjacent to the sacroiliac joint for both the DIC measured and the FE predicted cases, and were generated by the application of the hip joint reaction force and the constraint condition. Very low strains were observed at the superior part of the ilium, indicating predominant load transfer from the acetabulum to the sacroiliac joint. The strains for the implanted pelvis within the ROI ranged from 0 to $900 \mu \varepsilon$ (Figs. 5c and d). High strains varying from 600 to $900 \mu \varepsilon$ were observed at the posterior and the inferior part of the ilium, whereas the superior part of the ilium was virtually unloaded (Figs. 5c and d).

\subsection{Assessment of the correlation between the DIC measured and FE predicted strains}

The linear regression analysis (Table 1) and the scatter plots (Fig. 6) for both pelvises were based on discrete values of DIC measured and FE predicted strains. A high correlation coefficient $(\mathrm{R}=0.956)$ and a low standard error of estimates $(\mathrm{SE}=69.53 \mu \varepsilon)$ was obtained for the intact pelvis. The corresponding t-test demonstrated that this correlation was significant: t-statistic $=32.448, \mathrm{p}<0.0005$. The regression slope of $\mathrm{b}=0.85(\mathrm{SE}$ of $\mathrm{b}=3.05 \%)$ and intercept of $\mathrm{a}=50.32 \mu \varepsilon$ were indicative of a strong linear relationship between the DIC measured and FE predicted strains. For the implanted pelvis, regression analysis yielded a high $\mathrm{R}=0.938$ and a low $\mathrm{SE}=75.09 \mu \varepsilon$. A regression slope $\mathrm{b}=0.894(\mathrm{SE}$ of $\mathrm{b}=3.80 \%)$ and intercept $\mathrm{a}=45.85 \mu \varepsilon$ was found for this case. The paired $\mathrm{t}$-test for this data set demonstrated

that this correlation was significant: t-statistic $=26.368, \mathrm{p}<0.0005$. The results corresponding to unified data of intact and implanted pelvises, also indicated a high 
correlation coefficient $(\mathrm{R}=0.947)$ and a low $\mathrm{SE}=72.62 \mu \varepsilon$. A regression slope of $\mathrm{b}=0.866$ $(\mathrm{SE}$ of $\mathrm{b}=2.42)$ and an intercept $\mathrm{a}=50.64 \mu \varepsilon$ indicated a strong linear relationship between FE predicted and DIC measured strain (Table 1). The paired t-test for the unified data indicated that this correlation was significant: $\mathrm{t}$-statistic $=41.328, \mathrm{P}<0.0005$. Therefore, the DIC measured and FE predicted strains for both the pelvises were related to each other with a confidence level greater than $95 \%$.

\subsection{Comparison of measured strain values: DIC versus Strain rosette}

Discrete values of principal strain obtained from the DIC measurements were compared with the strain rosette readings at three different locations (1, 2 and 3), as shown in Table 2. In the intact pelvis, the DIC measured strains (first principal) at locations 1,2 and 3 were found to be $291 \mu \varepsilon, 161 \mu \varepsilon$ and $88 \mu \varepsilon$, respectively. In comparison, the corresponding strain rosette measurements of first principal strain were $292 \mu \varepsilon, 138 \mu \varepsilon$ and $81 \mu \varepsilon$. At the other two locations the corresponding strain data using two measurement techniques indicated similar agreement (Table 2). These results indicate that the DIC measurements corroborated well with the strain rosette readings.

\subsection{Comparison of strains: intact versus implanted pelvises}

The changes in strain distribution due to implantation are evident in the differences in DIC measured principal strains between the intact and implanted cases (Fig.7). An approximately $36 \%$ increase in principal strain was observed around the cortex of the acetabulum, based on data $(\mathrm{N}=125)$ collected in the virtual strain gauge area (Fig. 1a) after implantation, indicating increased load transfer through that region (Fig. 8). The stiff metallic cup produced increased strain at the cortex of the superior acetabular rim, which could potentially lead to strain shielding in the underlying cancellous bone. Moreover, a reduction of $6 \%$ and $42 \%$ in compressive strain was measured at locations 2 and 3, respectively, indicating the possibility of strain shielding at the central part of the ilium (Table 2). 


\section{Discussion}

The primary goal of the study was to test the validity of FE models of intact and implanted composite hemi pelvises, using a full field strain distribution measured by DIC. For the purpose of validation, von Mises (equivalent) strain on the bone surface was chosen since DIC measures 2-D full field strain, for which the principal strains are not directly comparable to the FE predicted 3-D strain distribution. However, to understand deviations in load transfer due to implantation, DIC measured principal strain components were considered in order to differentiate between compressive and tensile strains. Subsequently, in order to assess the validity of DIC measurements, discrete strain data was compared with those measured using strain rosettes. Although previous studies on the pelvis were based on localized measurements of surface strain using strain gauges $[1-3,6,35,36]$, there is a dearth of experimental data on full field strain distribution, which would be required for a more thorough validation of the FE predicted results.

Full field strain distributions for both the specimens were found to be very similar to the FE predicted strain patterns. However, some deviations in results were observed at locations around the curved irregular boundaries in the ROI, which may be attributed to the subtended acute angle in the viewing direction of the camera. The DIC measured and FE predicted strains in the higher range $(600-900 \mu \varepsilon)$ were found to be similar (Fig. 5), since the signal to noise ratio was high for this range. The one-to-one agreement between the DIC and FE strains exhibited a linear regression slope b of 0.850 for the intact model and 0.894 for the implanted model. The FE predictions may be over-estimated through a loss in thickness of the cortex structure in the model, arising from CAD model generation or FE meshing. An under-estimate of the Sawbone's Young's Modulus values could also lead to over-estimated FE strains, although the assigned values were those stated by the manufacturer (3405, Sawbones AG, Sweden). The DIC could also underestimate the peak strain due to averaging 
errors, particularly at highly curved boundaries of the ROI in the pelvises, and this is a limitation of the technique. In order to achieve more accurate results, especially in the highly curved regions, a finer speckle pattern should be generated on the specimen and the camera should be positioned closer, for greater deformation measurement sensitivity, and confidence in absolute strain levels. The close linear agreement, obtained for full field strain data, gave confidence in the validity of the presented model for comparative study such as that presented for implanted and intact cases.

These observations are well supported by a similar experimental study using DIC measurements on a composite proximal femur [10]. Despite some deviations, linear regression analysis indicated close agreement between the DIC measured and FE predicted strain, with a high correlation coefficient $(\mathrm{R}=0.93-0.95)$, a low SE of the estimate (69 $75 \mu \varepsilon)$, and a low PE in regression slope $(3-3.8 \%)$. These results indicate that the overall DIC measured strain distribution corroborated the FE predicted strains. Furthermore, quantitative agreement of DIC strain data with strain rosette measurements validates the DIC measurements and confirms that the full field results predicted by the FE models can be used as valid predictors of actual strains across the composite pelvis.

The observed load transfer patterns across the pelvis are similar to those reported in earlier experimental and numerical studies [1 - 3]. Strain patterns indicated that the hip joint contact force was predominantly transferred from the acetabulum to the sacroiliac joint, which was similar to the findings by Dalstra and Huiskes [30]. Implantation led to increased strain in the periacetabular cortical bone, and a reduction in strain or 'strain shielding' was observed at the central part of the ilium. These findings were supported by clinical observations [37 - 40] and FE analysis predictions [41 - 43]. The clinical study by Wright et al. [37], reported that the load is transmitted predominantly through the cup to the peripheral cortex of the acetabulum and the ilium, and consequently, the cancellous bone of the central 
part of the ilium is mechanically shielded. A clinical bone remodelling study around cementless acetabular components by Meneghini et al. [40] observed that relative bone density was increased in the periphery of the acetabulum, due to increased load transfer through that region. Laursen et al. [39] reported bone mineral density changes that stabilised over the first postoperative year, which is consistent with an adaptive bone remodelling process. Similar results were reported by Manley et al. [43], who observed using FE analysis that the implanted pelvis had less load transfer in the anterior and posterior regions of the acetabulum, and adjacent to the ischial facet as compared to the normal hip. An FE study on bone remodelling around the uncemented acetabulum by Levenston et al. [41] predicted bone loss of upto $50 \%$, medial to the prosthesis, due to stress shielding, and an increase in bone density of approximately $30 \%$ in the region of the acetabulum rim. Similar findings were reported by Wilkinson et al. [38], which corroborated that bone mineral density was increased around the acetabular rim and decreased in the medial portion of the acetabulum.

The present study has a number of limitations. The supporting fixture is not entirely representative of the in-vivo condition, where there are no rigid constraints. The constraint conditions were carefully designed in an attempt to reproduce a closer representation of the physiological supports than earlier studies [1 - 3], which featured large areas of rigid fixation. Whilst the study presents data to validate a computational model of the experiment, it does not validate the experimental boundary conditions as a representation of the in-vivo scenario. Instead of real bone, the experiment was carried out on a fourth generation composite hemipelvis, which is considered to be a viable alternative to the cadaveric bone for biomechanical evaluation of bone and implant-bone structures [44-52]. The composite bone specimen is a simpler structure than real bone, and does not contain fully representative material anisotropy or heterogeneity due to density variability. The composite pelvis represents a standardised geometry of pelvis, with gross structural behaviour close to that of the human pelvis, and 
unlike human cadaver pelvis it has very small inter-specimen variability. Moreover, the validation study is based on measurements of surface strains on the cortical bone. Only one loading condition within a normal walking cycle was used, and the action of muscle forces was not included in the model. Higher correlation between the DIC measured and FE predicted strains (Table 1) was observed for the intact pelvis $(\mathrm{R}=0.956)$ as compared to that of the implanted pelvis $(\mathrm{R}=0.938)$. This may be due to estimated values of interference fit and coefficient of friction between the implant and the underlying bone for the FE simulation. Since the purpose of the study was to validate the FE model using a representative yet analogue experimental model, real bone was not employed. It should, however, be noted that the accuracy of the DIC results is highly dependent on the resolution of the speckle coating, which may be difficult to apply on a real bone surface. Moreover, artifacts should be avoided while modifying the surface or applying a coating of white paint during specimen preparation. Despite these limitations, the study has shown that the FE models accurately characterized the strains on the bone surface in the intact and implanted experimental models, around the acetabulum and the iliac bone, when the acetabulum is loaded by a compressive force. The study also supports the validity of stresses and strain predictions within the model because surface strain is closely related to stresses and strain inside the bone.

\section{Conclusions}

In a test of the validity of FE models of intact and implanted composite hemi pelvises, FE predicted full field strain distributions were in close agreement with those measured experimentally, by Digital Image Correlation. Additionally, agreement between strain rosette measurements and discrete DIC strain measurements supports the validity of the DIC technique for strain measurement in physically representative bone constructs. Based on this study, it may be concluded that the FE model can be used as a valid predictor of the experimentally measured full field strain in the intact and implanted composite pelvis models. 
This confirms its suitability for further computational investigations on the changes in load transfer around the acetabulum and the iliac bone due to implantation with new and existing acetabular cup designs, as a pre-clinical analysis tool.

\section{Acknowledgements}

The authors would like to thankfully acknowledge the UKIERI British Council, Finsbury Orthopaedics Ltd., UK and the Department of Biotechnology, New Delhi, for supporting this study.

\section{Conflict of interest}

The authors hereby declare that with regard to the submission of this article there are no financial or personal relationships with other people and organisations.

\section{References}

[1] Dalstra, M., Huiskes, R., and van Erning, L., 1995, "Development and validation of a three-dimensional finite element model of the pelvic bone”, ASME J. Biomech. Eng., 117, pp. $272-278$.

[2] Anderson, A.E., Peters, C.L., Tuttle, B.D., and Weiss, J.A., 2005, “Subject-specific finite element model of the pelvis: Development, validation, sensitive studies", ASME J. Biomech. Eng., 127, pp. $364-373$.

[3] Zhang, Q.H., Wang, J.Y., Lupton, C., Adegbile, P.H., Guo, Z.X., Liu, Q., and Tong, J., 2010, “A subject-specific pelvic bone model and its application to cemented acetabular replacements", J. Biomech., 43, pp. $2722-2727$.

[4] Pal, B., Gupta, S., New, A.M.R., and Browne, M., 2010, "Strain and micromotion in intact and resurfaced composite femurs: Experimental and numerical Investigations”, J. Biomech., 43, pp. $1923-1930$. 
[5] Dally, J.W. and Railey, W.F., 1991, "Experimental stress analysis", 3rd sub. Ed., McGraw-Hill College, Boston, MA.

[6] Miles, A.W., and McNamee, P.B., 1989, "Strain gauge and photoelastic evaluation of the load transfer in the pelvis in total hip replacement: The effect of the position of the axis of the rotation”, Proc. Inst. Mech. Eng., Part H: J. Eng. Med., 203, pp. 103 - 107.

[7] Everitt, H., Evans, S. L., Holt, C. A., Bigsby, R., and Khan, I., 2010, “Acetabular component deformation under rim loading using digital image correlation and finite element methods", App. Mech. Mat., 24-25, pp. 275 - 280.

[8] Sztefek, P., Vanleene, M., Olsson, R., Collinson, R., Pitsillides, A. A., and Shefelbine, S., 2010, " Using digital image correlation to determine bone surface strains during loading and after adaptation of mouse tibia”, J. Biomech., 43, pp. $599-605$.

[9] Tayton, E., Evans, S., and O’Doherty, D., 2010, "Mapping the strain distribution on the proximal femur with titanium and flexible stemmed implants using digital image correlation”, J. Bone Joint Surg. Br., 92, pp. $1176-1181$.

[10] Dickinson, A. S., Taylor, A. C., Ozturk, H., and Browne, M., 2011, "Experimental validation of a finite element model of the proximal femur using digital image correlation and a composite bone model”, ASME J. Biomech. Eng., 133, pp. 1 - 6.

[11] Verhulp, E., van Ritbergen, B., and Huiskes, R., 2004, “A three-dimensional digital image correlation technique for strain measurements in microstructures”, J. Biomech., 37, pp. $1313-1320$.

[12] Tiossi, R., Lin, L., Rodrigues, R. C. S., Heo, Y. C., Conrad, H. J., Mattos, M. G. C., Ribeiro, R. F., and Fok, A. S. L., 2011, "Digital image correlation analysis of the load transfer by implant-supported restorations”, J. Biomech., 44, pp. $1008-1013$. 
[13] Zhang, D., Eggliton, C. D., and Arola, D. D., 2002, "Evaluating the mechanical behavior of arterial tissue using Digital Image Correlation”, Experimental Mechanics, 42, pp. 409 416.

[14] Brown, A. N., McKinley, T. O., and Bay, B. K., 2002, “Trabecular bone strain changes associated with subchondral bone defects of the tibia plateau", J. Orthop. Trauma, 16, pp. 638 $-643$.

[15] Zhang, D., and Arola, D.D., 2004, “Application of digital image correlation to biological tissues", J. Biomed. Optics, 9, pp. $691-699$.

[16] Thompson, M. S., Schell, H., Lienau, J., and Duda, G. N., 2007, "Digital image correlation: A technique for determining local mechanical conditions within early bone callus”, Med. Engng. Phys., 29, pp. 820 - 823.

[17] Moerman, K. M., Holt, C. A., Evans, S. L., and Simms, C. K., 2009, "Digital image correlation and finite element modelling as a method to determine mechanical properties of human soft tissue in vivo", J. Biomech., 42, pp. 1150 - 1153.

[18] Evans, S. L., and Holt, C. A., 2009, "Measuring the mechanical properties of human skin in vivo using digital image correlation and finite element modelling", The J. Strain Analysis Engng. Design, 44, pp. $337-345$.

[19] Tanasic, I., Milic-Lemic, A., Tihacek-Sojic, L., Stancic, I., and Mitrovic, N., 2011, "Analysis of the compressive strain below the removable and fixed prosthesis in the posterior mandible using a digital image correlation method," Biomech. Modelling Mechano., In Press. [20] Dickinson, A. S., Taylor, A. C., and Browne, M., 2012, "The influence of acetabular cup material on pelvis cortex surface strains, measured using digital image correlation," J. Biomech., 45, pp. $719-723$.

[21] Bay, B. K., 1995, “Texture correlation: A method for the measurement of detailed strain distributions within trabecular bone”, J. Orthop. Res., 13, pp. 258 - 267. 
[22] Christopher, L. G., Qing, X., Setton, L. A., and Hsu, E. W., 2003, “A first-order texture correlation algorithm and image roughness parameter to quantify soft tissue deformation using MRI, Summer Bioengineering Conference, Key Biscayne, Florida, June 25 - 29.

[23] Sviridov, A. P., Ulissi, Z., Chernomordik, V., Hassan, M., and Gandjbakhche, A. H., 2006, "Visualization of biological texture using correlation coefficient images", J. Biomed. Optics., 11, $060504(1-3)$.

[24] Liu, L., and Morgan, E. F., 2007, “Accuracy and precision of digital volume correlation in quantifying displacements and strains in trabecular bone", J. Biomech., 40, 3516 - 3520.

[25] Bremand, F., Germaneau, A., Doumalin, P., and Dupre, J. C., 2008, "Study of mechanical behaviour of cancellous bone by digital volume correlation and X-ray microcomputed tomography”, Proceedings of XIth International Congress and Exposition, Orlando, Florida, USA, June 2 - 5.

[26] Frost, H. M., 1990, "Skeletal structural adaptations to mechanical usage (SATMU): 2. Redefining Wolff's Law: The remodeling problem”, Anat. Rec., 224 (4), 414 - 422.

[27] Lewinnek, G.E., Lewis, J.L., Tarr, R., Compere, C.L., and Zimmerman, J.R., 1978, "Dislocations after total hip-replacement arthroplasties", J. Bone Joint Surg. Am., 60 (2), pp. $217-220$.

[28] Janssen, D., Zwartele, R.E., Doets, H.C., and Verdonschot, N., 2009, “Computational assessment of press-fit acetabular implant fixation: The effect of implant design, interference fit, bone quality, and frictional properties”, Proc. Inst. Mech. Eng., Part H: J. Eng. Med., 224, pp. $65-75$.

[29] Spears, I.R., Pfleiderer, M., Schneider, E., Hailee, E., and Morlock, M.M., 2001, “The effect of interfacial parameters on cup-bone relative micromotions: A finite element investigation”, J. Biomech., 34, pp. 113 - 120. 
[30] Dalstra, M., and Huiskes, R., 1995, "Load transfer across the pelvis bone”, J. Biomech, 28, pp. 715-724.

[31] Phillips, A.T.M., Pankaj, P., Howie, C.R., Usmani, A.S. and Simpson, A.H.R.W., 2007, "Finite element modelling of the pelvis: inclusion of muscular and ligamentous boundary conditions”, Med. Engng. Phys., 29 (7), 739 - 748.

[32] Spears, I.R., Pfleiderer, M., Schneider, E., Hailee, E., Bergmann, G., and Morlock, M.M., 2000, "Interfacial conditions between a press-fit acetabular cup and bone during daily activities: Implications for achieving bone in-growth”, J. Biomech., 33, 1471 -1477.

[33] Viceconti, M., Muccini, R., Bernakiewicz, M., Baleani, M., and Cristofolini, L., 2000, "Large-sliding contact elements accurately predict levels of bone-Implant micromotion relevant to osseointegration”, J. Biomech., 33, 1611 - 1618.

[34] Vic-3D Testing Guide 2009, Correlated Solutions Inc., SC, USA.

[35] Lionberger, D., Walker, P.S., and Granholm, J., 1985, "Effect of prosthetic acetabular replacement on strains in the pelvis", J. Orthop. Res., 3, pp. $372-379$.

[36] Massin, P., Vandenbussche, E., Landjerit, B., and Augereau, B., 1996, "Experimental study of periacetabular deformations before and after implantation of hip prosthesis", J. Biomech., 29, pp. $53-61$.

[37] Wright, J. M., Pellicci, P. M., Salvati, E. A., Ghelman, B., Roberts, M. M., and Koh, J.L., 2001, "Bone density adjacent to press-fit acetabular components: A prospective analysis with quantitative computer tomography”, J. Bone Joint Surg. Am., 83, pp. $529-536$.

[38] Wilkinson, J.M., Peel, N.F., Elson, R.A., Stockley, I., and Eastell R., 2001, "Measuring bone mineral density of the pelvis and proximal femur after total hip arthroplasty”, J. Bone Joint Surg. Br, 83, pp. 283-288. 
[39] Laursen, M. B., Nielsen, P. T., and Soballe, K., 2007, "Bone remodeling around HA coated acetabular cup”, Inter. Orthopaedics, 31, pp. 199 - 204.

[40] Meneghini, R.M., Ford, K.S., McCollough, C.H., Hanssen, A.D., Lewallen, and D.G., 2010, "Bone remodelling around porous metal cementless acetabular component", J. Arthroplasty, 25, pp. 741-747.

[41] Levenston, M.E., Beaupre, G.S., Schurman, D.J., and Carter D.R., 1993, “Computer simulations of stress-related bone remodeling around noncemented acetabular components", J. Arthroplasty, 8, pp. 595-605.

[42] Thompson, M.S., Northmore-Ball, M.D., and Tanner, K.E., 2002, "Effect of acetabular resurfacing component material and fixation on the strain distribution in the pelvis", Inst. Mech. Eng., Part H: J. Eng. Med., 216, pp. $237-245$.

[43] Manley, M. T., Ong, K. L., and Kurtz, S. M, 2006, "The potential for bone loss in acetabular structures following THA”, Clin. Orthop. Rel. Research, 453, pp. $246-253$.

[44] Stolk, J., Verdonschot, N., Cristofolini, L., Toni, A., and Huiskes, R., 2002, "Finite element and experimental model of cemented hip joint reconstructions can produce similar bone and cement strains in pre-clinical tests", J. Biomech., 35(4), $499-510$.

[45] Waide, D., Cristofolini, L., Stolk, J., Verdonschot, N., and Toni, A., 2003, "Experimental investigations of bone remodelling using composite femurs", Clin. Biomech., $18(6), 523-536$.

[46] Cristofolini, L., Erani, P., Juszczyk, E. B., Ohashi, H., Iida, S., Minato, I., and Viceconti, M., 2010, "Effect of undersizing on the long-term stability of the Exeter hip stem: A comparative in vitro study", Clin. Biomech., 25(9), 899 - 908. 
[47] Grant, J. A., Bishop, N. E., Gotzen, N., Sprecher, C., Honl, M., and Morlock, M. M., 2007, “Artificial composite bone as a model of human trabecular bone: The implant bone interface” J. Biomech., 40(5), 1158 - 1164.

[48] Bolland, B. J. R. F., New, A. M. R., Madabhushi, S. P. G., Oreffo, R. O. C., and Dunlop, D. G., 2007, "Vibration assisted bone-graft compaction in impaction bone grafting of the femur”, J. Bone Jt Surg. Br., 89(5), $686-692$.

[49] Bougherara, H., Zdero, R., Mahboob, Z., Dubov, A., Shah, S., and Schemitsch, E. H., 2010, "The biomechanics of a validated finite element model of stress shielding in a novel hybrid total knee replacement”, Proc. IMechE, Part H: J. Engineering in Medicine, 224(H10), $1209-1219$.

[50] Grover, P., Albert, C., Wang, M., and Harris, G. F., 2011, "Mechanical characterization of fourth generation composite humerus", Proc. IMechE, Part H: J. Engineering in Medicine, 225(H12), $1169-1176$.

[51] Kaiser, M. M., Wessel, L. M., Zachert, G., Stratmann, C., Eggert, R., Gros, N., Hessing, M. S., Kienast, B., and Rapp, M., 2011, "Biomechanical analysis of a synthetic femur spiral fracture model: Influence of different materials on the stiffness in flexible intramedullary nailing”, Clin. Biomech., 26(6), 592 - 597.

[52] Fottner, A., Schmid, M., Birkenmaier, C., Mazoochian, F., Plitz., W., and Jansson, V., 2009, "Biomechanical evaluation of two types of short-stemmed hip prostheses compared to trust plate prosthesis by three dimensional measurement of micromotion", Clin. Biomech., $24(5), 429-434$. 


\section{Figures}

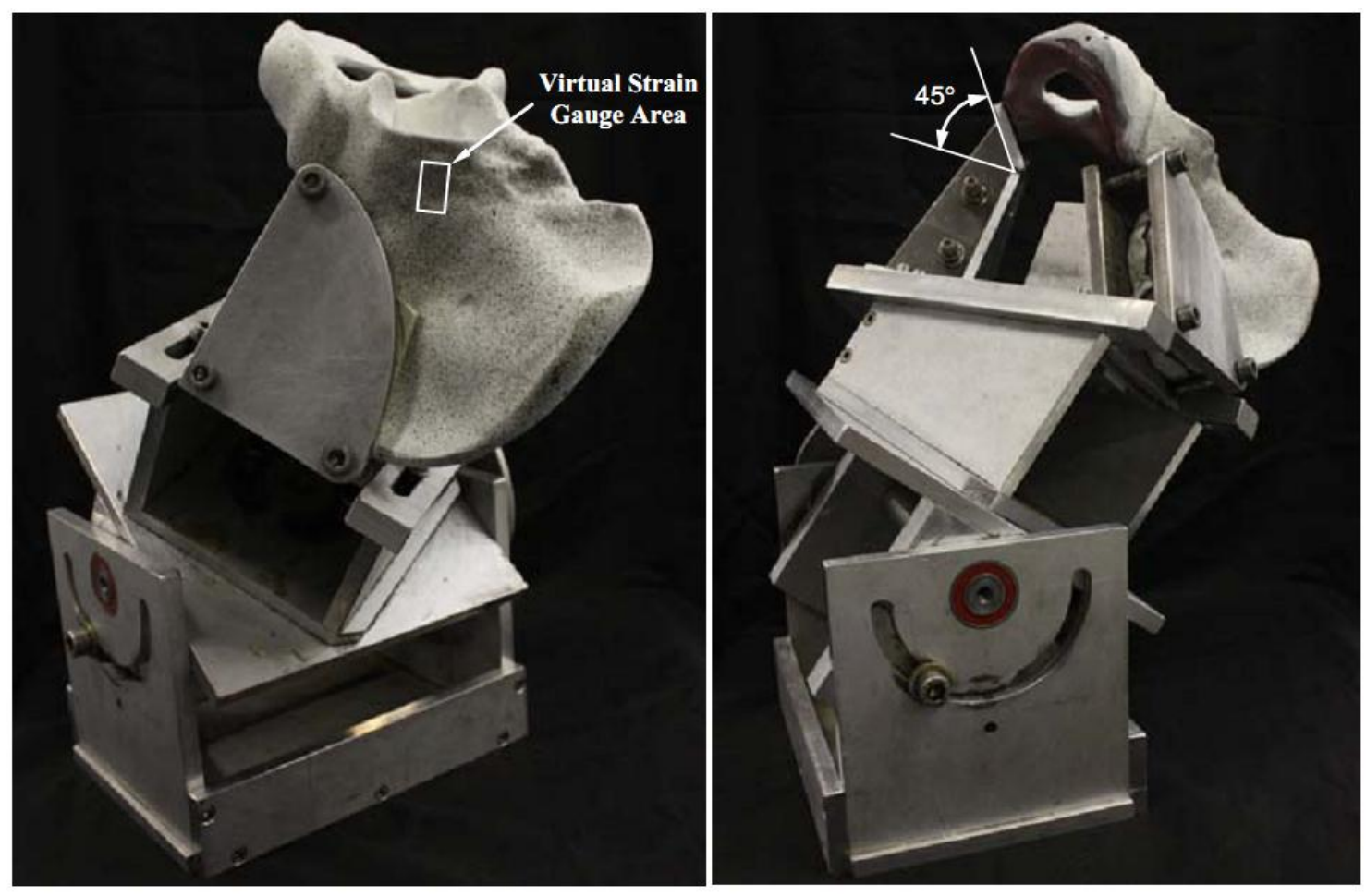

(a)

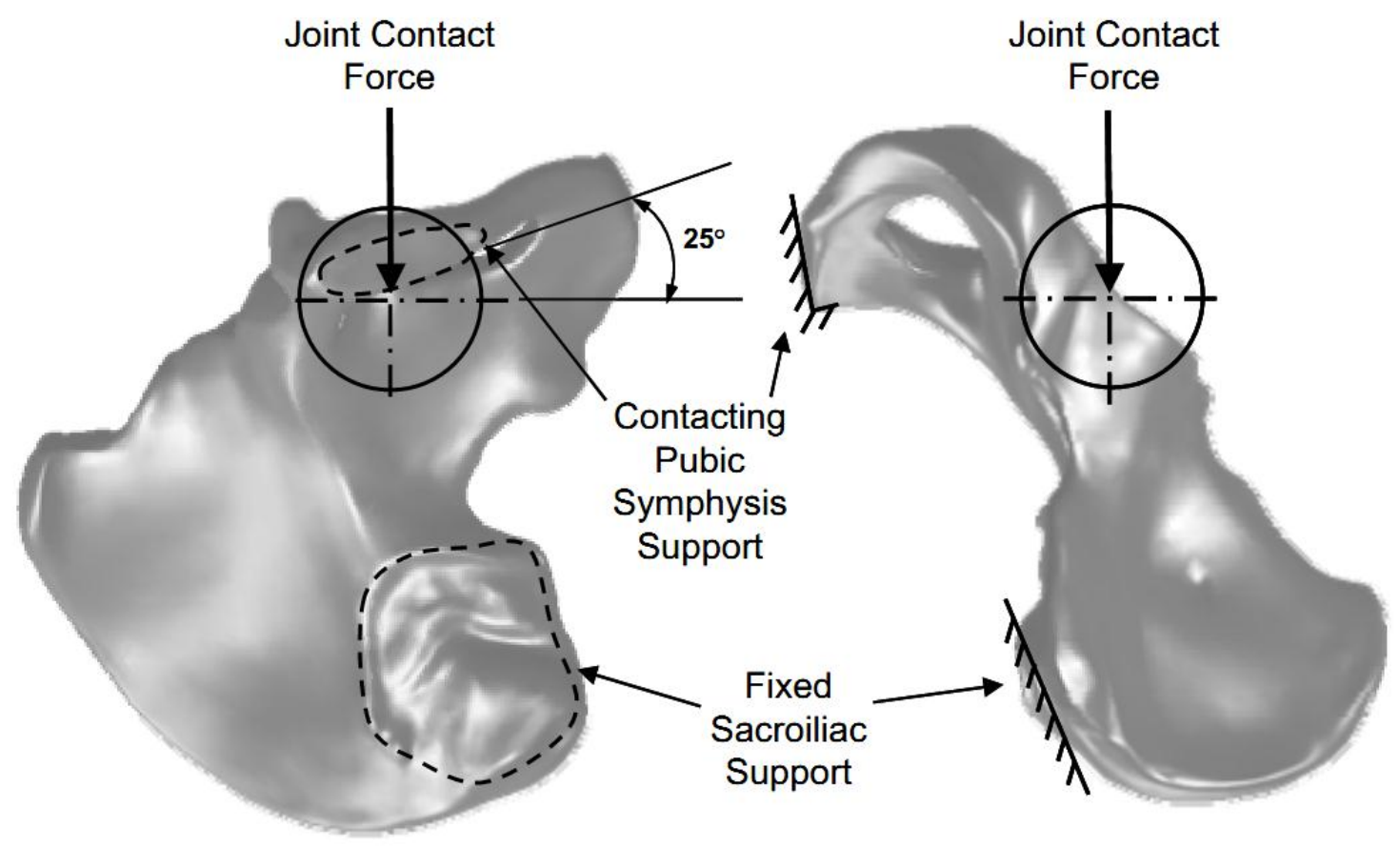

(b)

Figure 1. Fixture used to hold the pelvises, (a) lateral view showing speckle pattern and posterior view, (b) schematic representation of the support conditions; fixed boundary condition applied at sacro-iliac joint and supero-posterior part of the ilium, displacements are restrained along outward normal directions on the three faces of the pubis. 


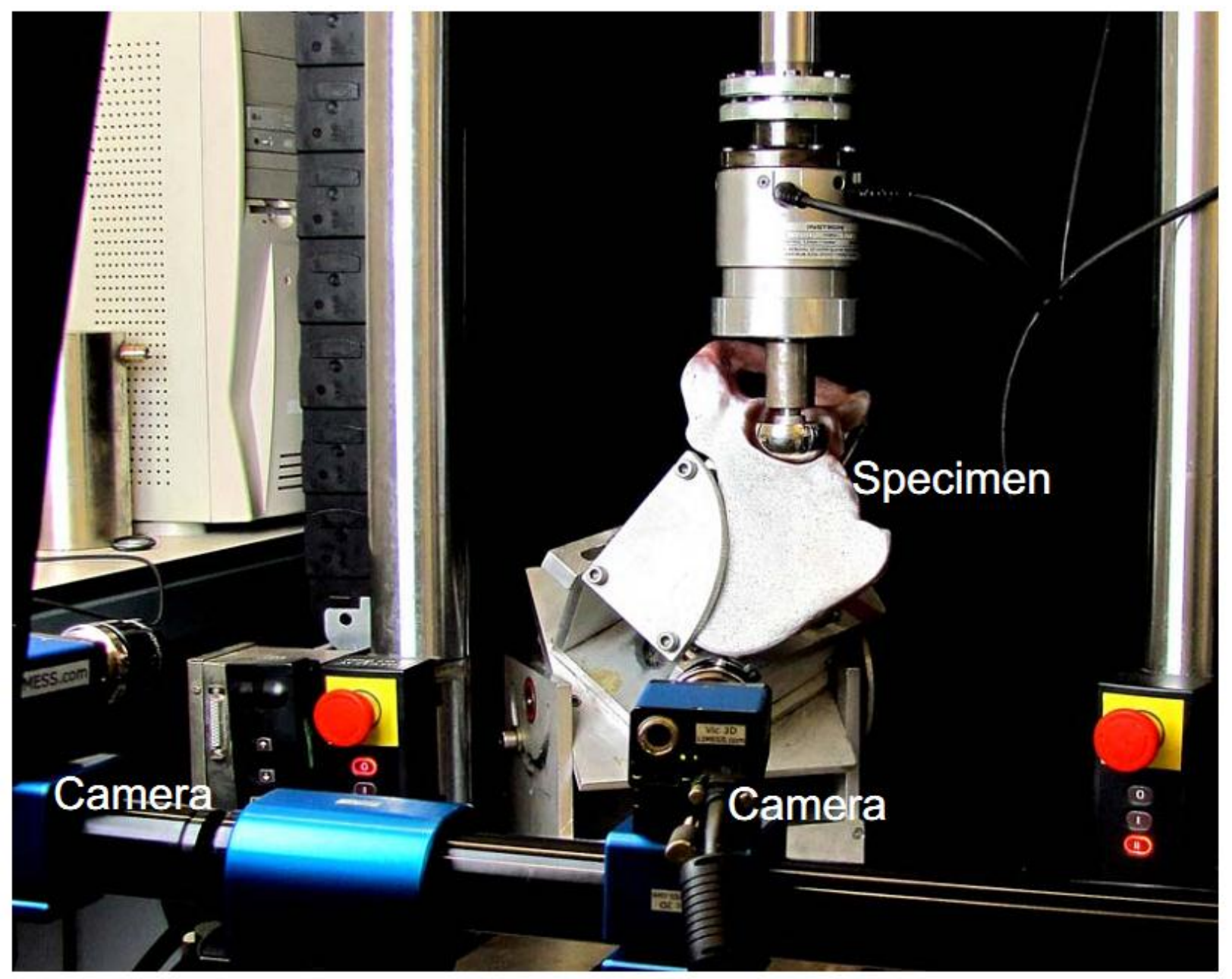

Figure 2. The experimental set-up for DIC measurement along with the loading mechanism for the pelvis. 



Figure 3. Location of strain rosettes and experimental set-up for strain rosette experiment.

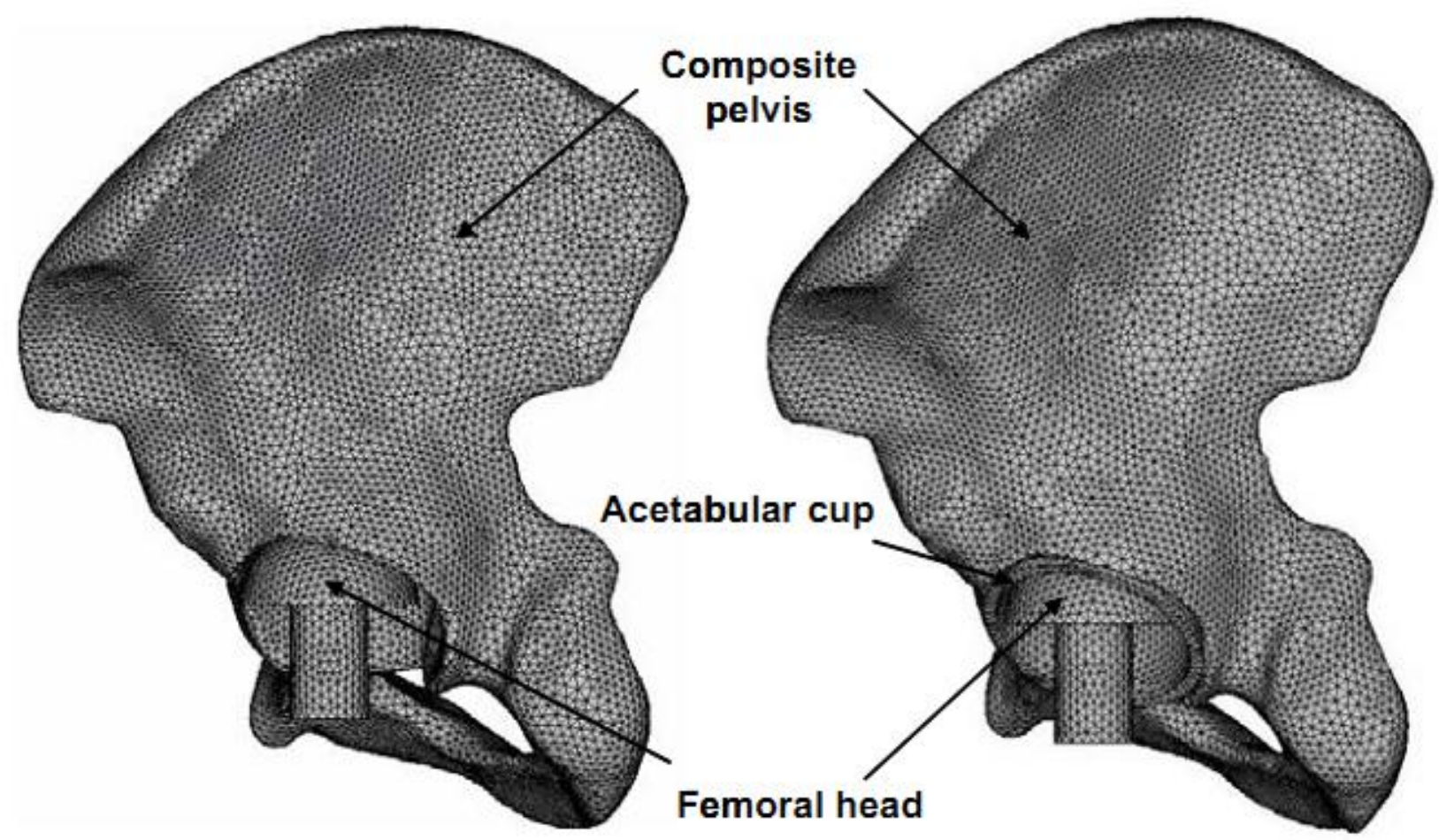

Figure 4. FE models of the composite pelvises. 


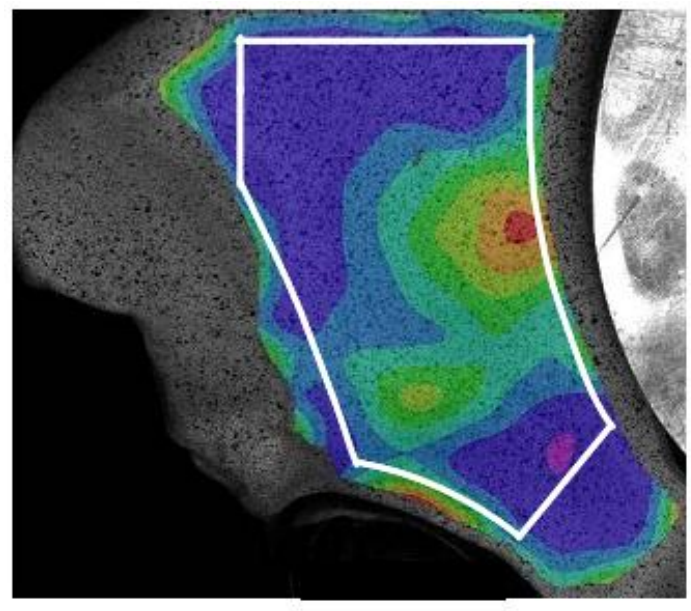

(a)

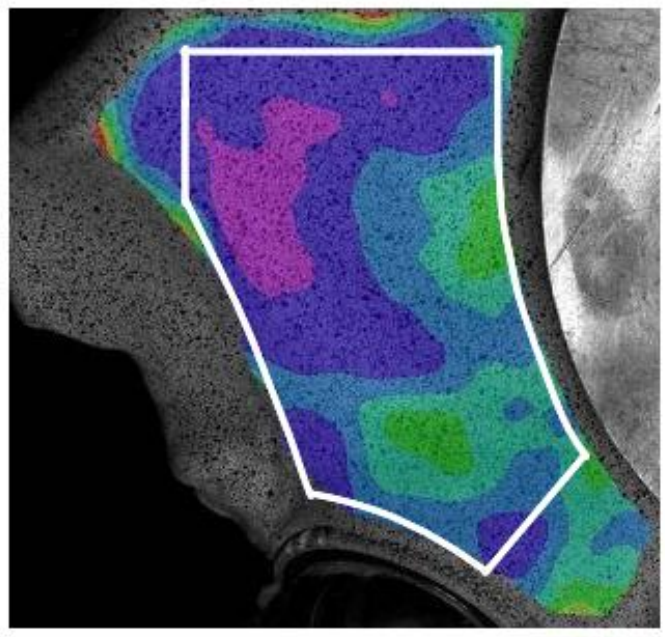

(c)

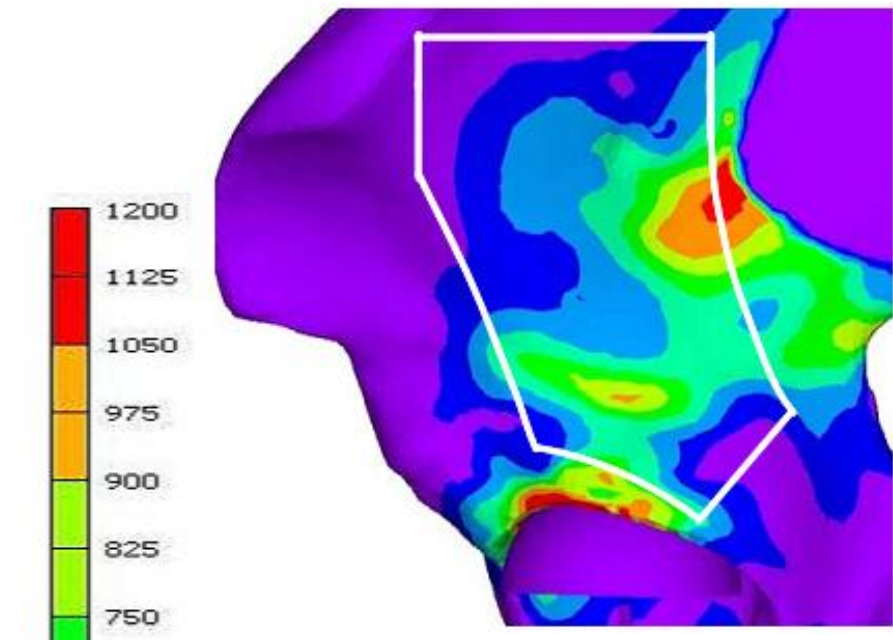

(b)

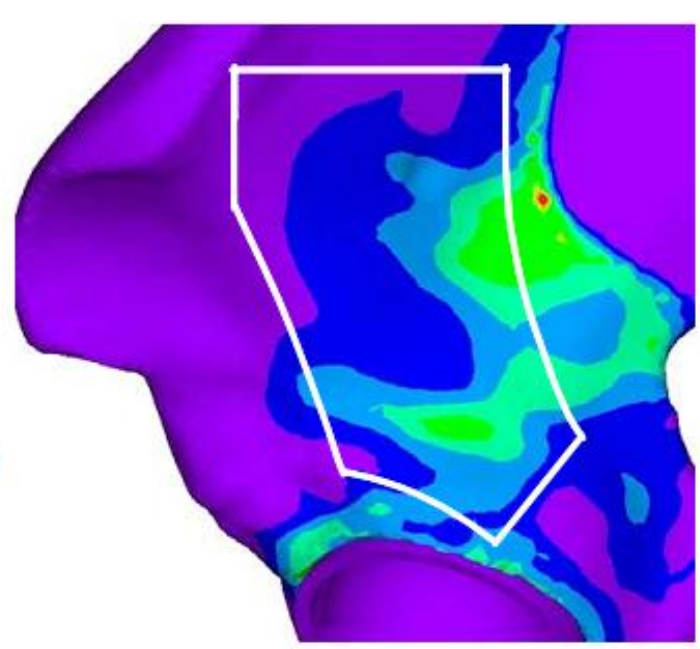

(d)

Figure 5. Distributions of von Mises strain ( $\mu \varepsilon$ ) in the tested pelvises, (a) DIC measured: intact; (b) FE predicted: intact; (c) DIC measured: implanted; (d) FE predicted: implanted. 


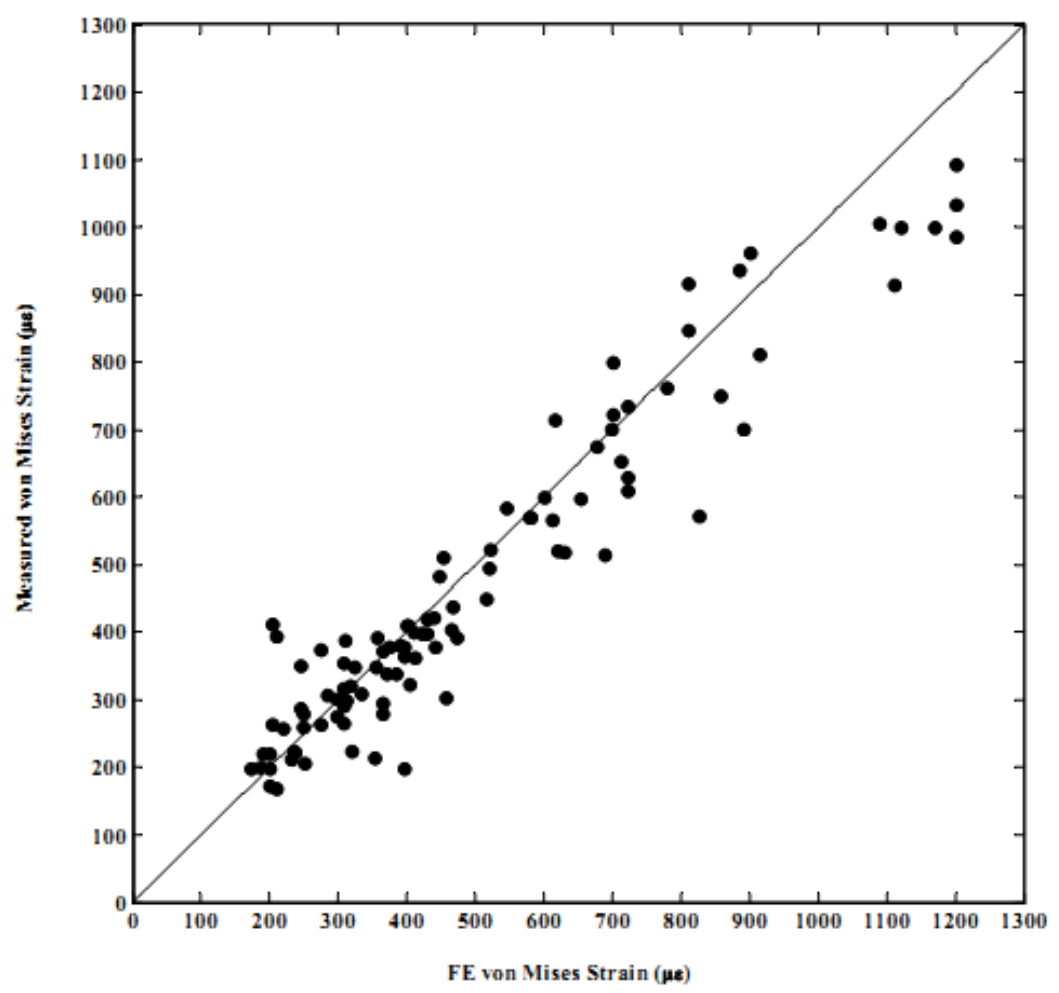

(a)

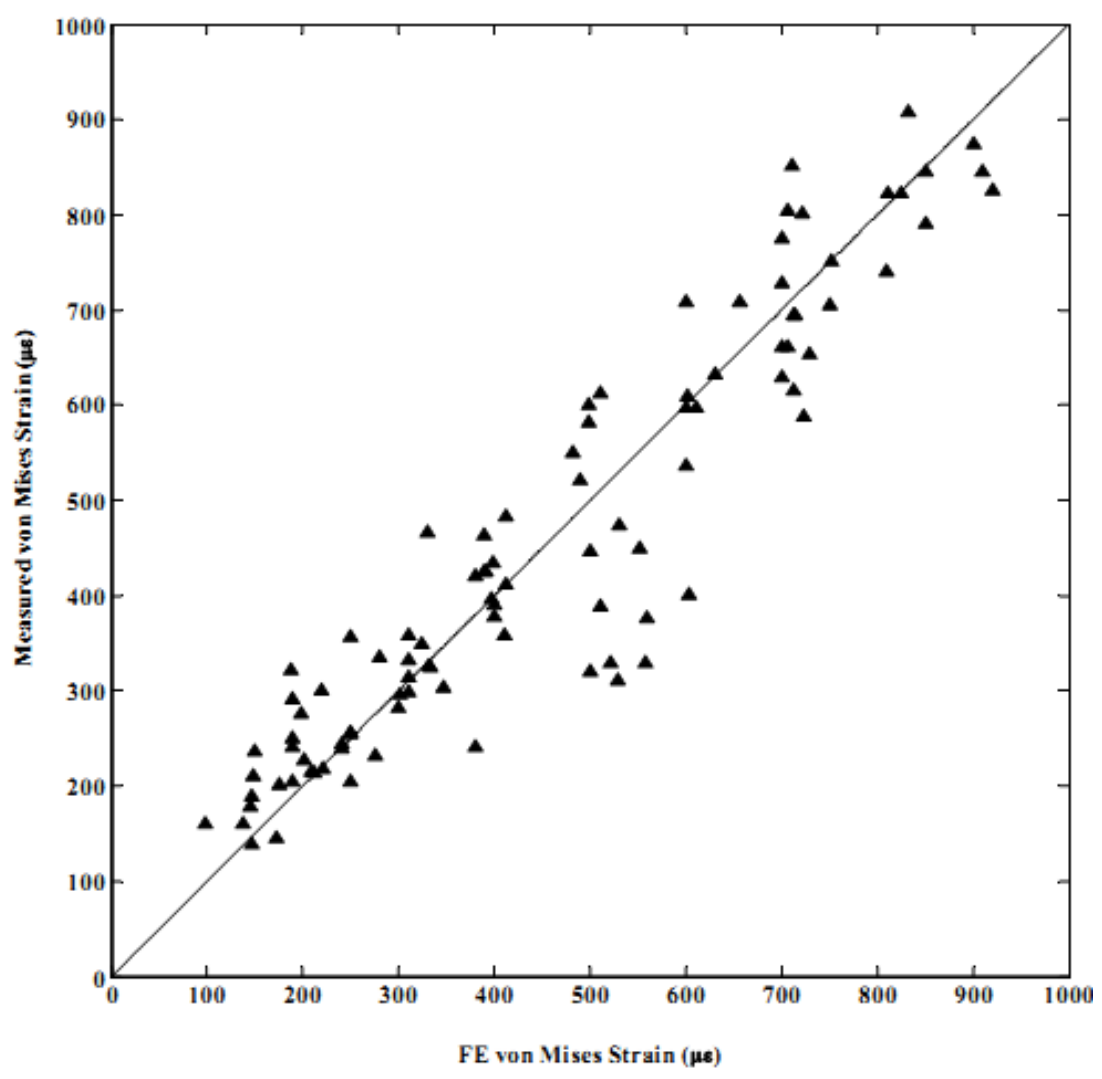

Figure 6. Measured DIC strain $(\mu \varepsilon)$ plotted against FE predicted strain $(\mu \varepsilon)$ with respect to the ideal line $($ slope $=1$, intercept $=0$ ) for load $1400 \mathrm{~N}$, (a) intact pelvis; (b) implanted pelvis. 


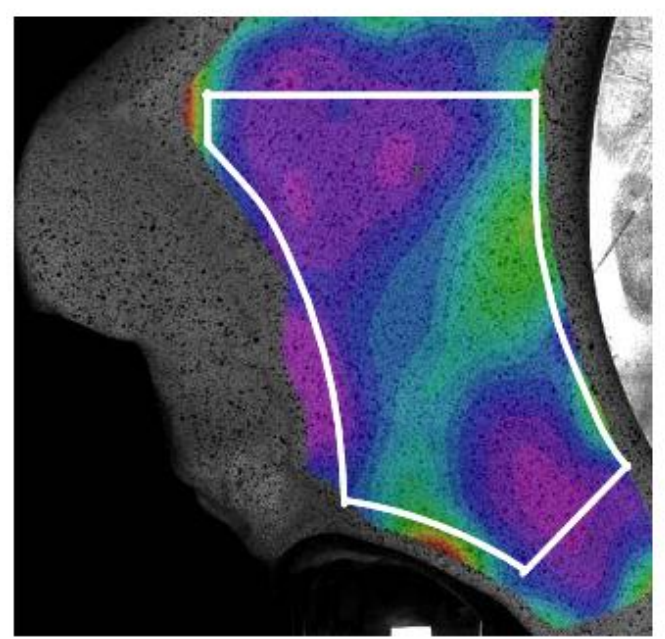

(a)

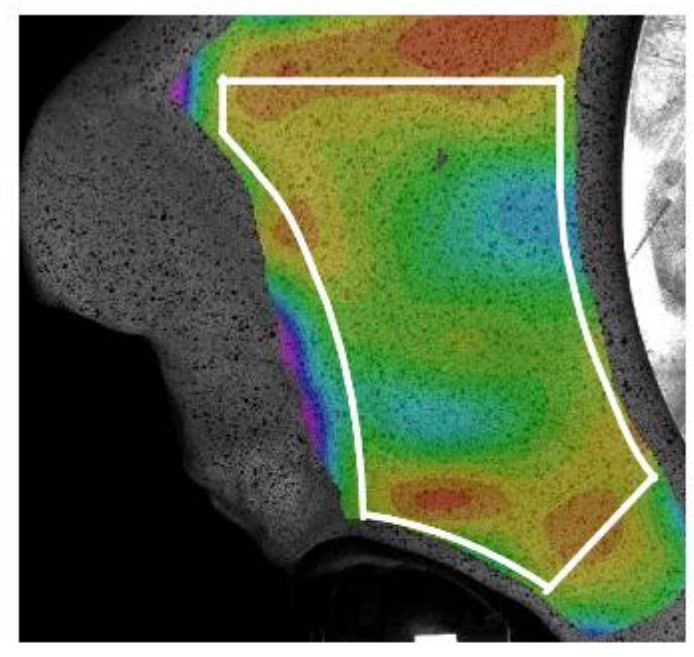

(c)
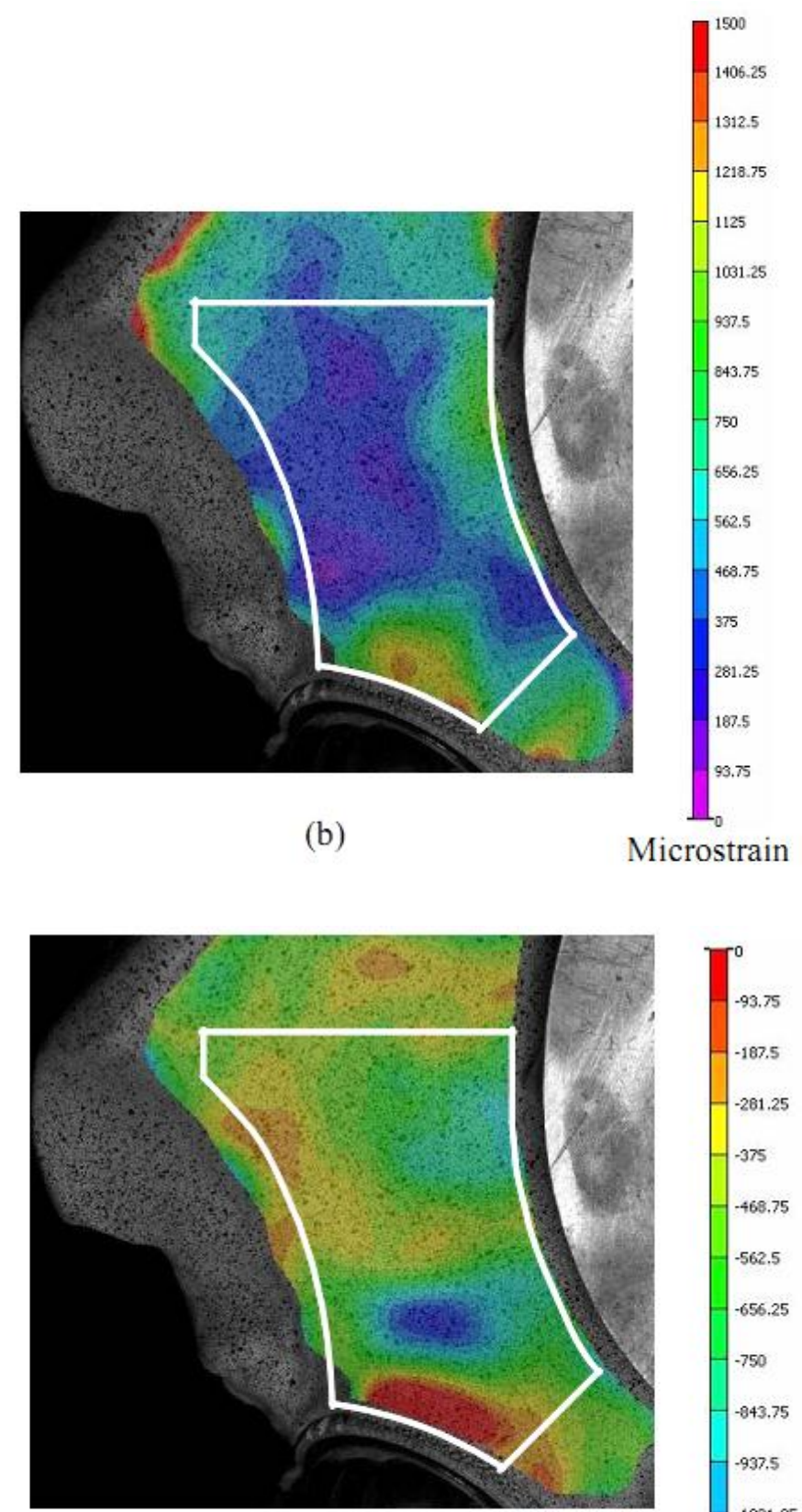

(d)

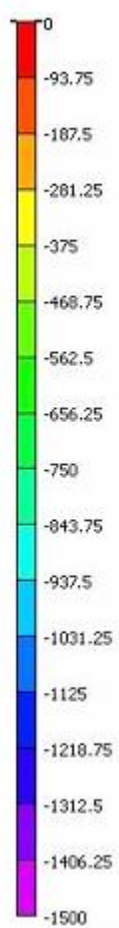

Figure 7. DIC measured principal strain $(\mu \varepsilon)$ distributions, (a) first principal: intact; (b) first principal: implanted; (c) second principal: intact; (d) second principal: implanted. 


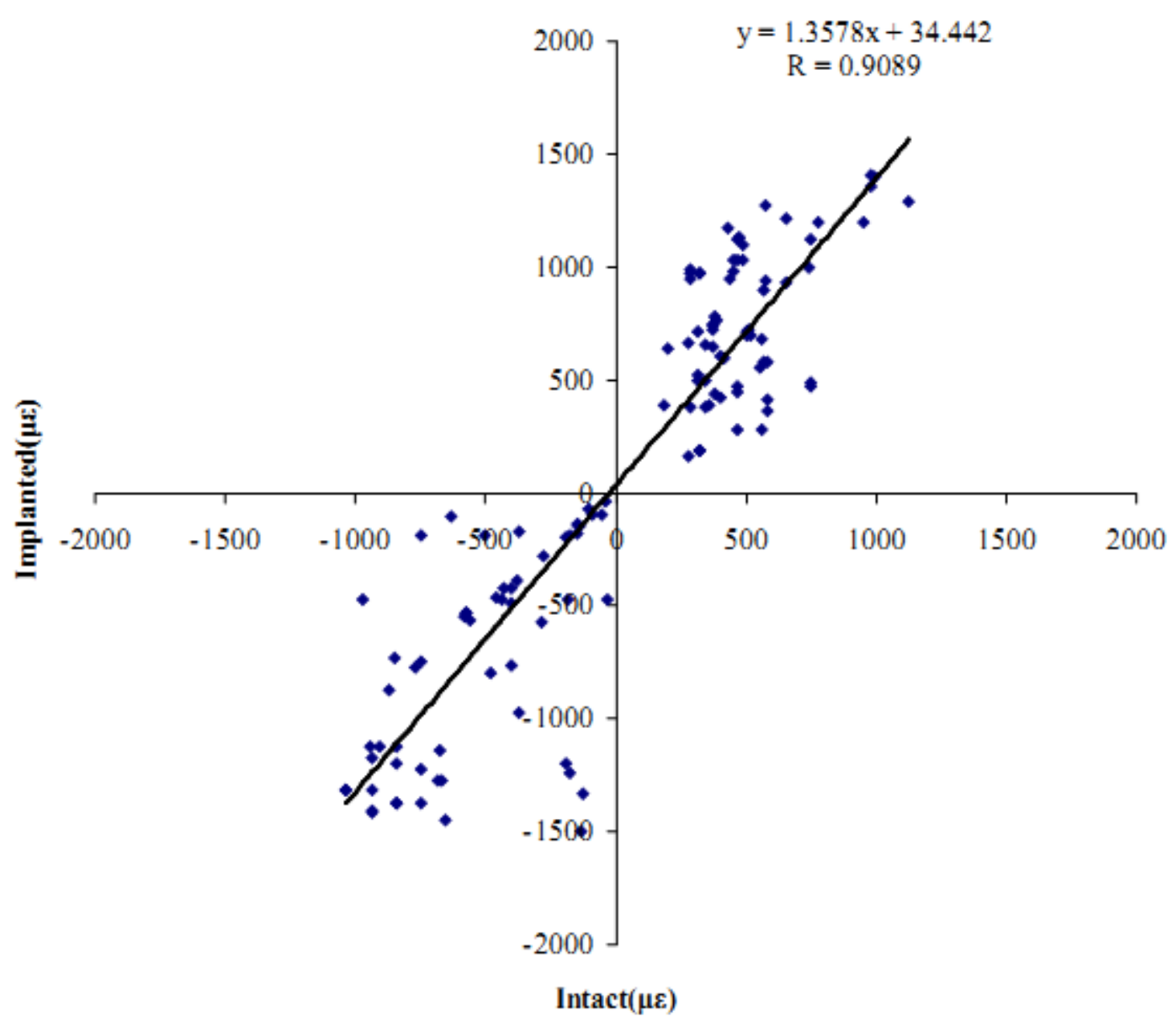

Figure 8. Comparison of DIC measured principal strains in the virtual strain gauge area for the intact and the implanted pelvises. 


\section{Tables}

Table 1. Regression analysis of the FE predicted and DIC measured von Mises strain $(\mu \varepsilon)$ for intact and implanted pelvis for load 1400 N. N is the number of data points.

\begin{tabular}{|c|c|c|c|c|c|c|c|}
\hline \multirow[t]{2}{*}{$\begin{array}{c}\text { Pelvis } \\
\text { Specimen }\end{array}$} & \multirow[t]{2}{*}{$\begin{array}{c}\text { Correlation } \\
\text { coefficient }(\mathrm{R})\end{array}$} & \multirow[t]{2}{*}{$\begin{array}{l}\text { Standard error } \\
\text { (SE) in } \mu \varepsilon\end{array}$} & \multicolumn{2}{|c|}{$\begin{array}{c}\text { Linear Regression } \\
y=a+b x\end{array}$} & \multirow[t]{2}{*}{$\begin{array}{l}\text { Standard error } \\
\text { (SE) of b }\end{array}$} & \multirow[t]{2}{*}{$\begin{array}{l}\% \text { error } \\
(\mathrm{PE}) \text { of } b\end{array}$} & \multirow[t]{2}{*}{$\begin{array}{l}\text { t-statistic } \\
\text { (P value) }\end{array}$} \\
\hline & & & $\mathrm{a}$ & $\mathrm{b}$ & & & \\
\hline $\begin{array}{c}\text { Intact } \\
(\mathrm{N}=100)\end{array}$ & 0.956 & 69.53 & 50.32 & 0.85 & 0.026 & 3.05 & $\begin{array}{l}32.448 \\
(0.000)\end{array}$ \\
\hline $\begin{array}{l}\text { Implanted } \\
(\mathrm{N}=100)\end{array}$ & 0.938 & 75.09 & 45.858 & 0.894 & 0.034 & 3.80 & $\begin{array}{l}26.368 \\
(0.000)\end{array}$ \\
\hline $\begin{array}{l}\text { All data } \\
(\mathrm{N}=200)\end{array}$ & 0.947 & 72.62 & 50.64 & 0.866 & 0.021 & 2.42 & $\begin{array}{l}41.328 \\
(0.000)\end{array}$ \\
\hline
\end{tabular}


Table 2. Measured principal strain $(\mu \varepsilon)$ using DIC $( \pm 17 \mu \varepsilon)$ and strain rosette $( \pm 8 \mu \varepsilon)$ techniques at three locations for the intact and the implanted pelvises. For strain rosette locations see Fig. 3.

\begin{tabular}{|c|c|c|c|c|c|c|c|}
\hline \multirow{3}{*}{$\begin{array}{c}\text { Pelvis } \\
\text { Specimen }\end{array}$} & Strain & \multicolumn{2}{|c|}{ Location 1 } & \multicolumn{2}{c|}{ Location 2 } & \multicolumn{2}{c|}{ Location 3 } \\
\cline { 2 - 8 } & $\begin{array}{c}\text { DIC } \\
(\mu \varepsilon)\end{array}$ & $\begin{array}{c}\text { SR } \\
(\mu \varepsilon)\end{array}$ & $\begin{array}{c}\text { DIC } \\
(\mu \varepsilon)\end{array}$ & $\begin{array}{c}\text { SR } \\
(\mu \varepsilon)\end{array}$ & $\begin{array}{c}\text { DIC } \\
(\mu \varepsilon)\end{array}$ & $\begin{array}{c}\text { SR } \\
(\mu \varepsilon)\end{array}$ \\
\hline \multirow{3}{*}{ Intact } & First principal & 291 & 292 & 161 & 138 & 88 & 81 \\
\cline { 2 - 8 } & Second principal & -285 & -255 & -402 & -484 & -279 & -268 \\
\hline \multirow{3}{*}{ Implanted } & First principal & 338 & 320 & 145 & 177 & 62 & 26 \\
\cline { 2 - 8 } & Second principal & -173 & -189 & -379 & -323 & -162 & -147 \\
\hline
\end{tabular}

